\title{
Non-Sterile Medical Gas Filling Method
}

National Cancer Institute

\section{Source}

National Cancer Institute. Non-Sterile Medical Gas Filling Method. NCI Thesaurus. Code C112993.

A process that fills a container with a purified medical gas, which is not performed under sterile conditions. 